\title{
Common Factors of the Exchange Risk Premium in
}

\section{Emerging European Markets*}

\author{
Joseph P. Byrne \\ Economics \\ University of Glasgow \\ UNITED KINGDOM
}

\author{
Jun Nagayasu \\ Graduate School of Systems and \\ Information Engineering \\ University of Tsukuba, JAPAN
}

24 May 2011

\begin{abstract}
:
Existing empirical evidence suggests that the Uncovered Interest Rate Parity (UIRP) condition may not hold due to an exchange risk premium. For a panel data set of eleven emerging European economies we decompose this exchange risk premium into an idiosyncratic (country-specific) element and a common factor using a principal components approach. We present evidence of stationary idiosyncratic and common factors. This result leads to the conclusion of a stationary risk premium for these countries, which is consistent with previous studies often documenting a stationary premium in developed countries. Furthermore, we report that the variation in the premium is largely attributable to a common factor influenced by economic developments in the United States.
\end{abstract}

JEL Classification: F41

Keywords: Uncovered Interest Rate Parity, Emerging Economies, Exchange Risk Premiums, Common Factors.

\footnotetext{
* Byrne: Economics, Adam Smith Building, Bute Gardens, University of Glasgow, Glasgow, G12 8RT, UK. E-mail: <joseph.byrne@ @lasgow.ac.uk>. Tel: +44 (0)141 330 4617. Fax: +44 (0)141 330 4940. Nagayasu acknowledges financial support in the form of a Grant-in-Aid for Science Research (Kakenhi, Kiban Kenkyu (C) No. 21530206.
} 


\section{Introduction}

Emerging countries are typically perceived to be susceptible to economic risk and uncertainty to a greater extent than industrial countries. This risk can originate domestically or internationally, and is important because, for example, external shocks that impact upon exchange rates create a 'fear of floating' exchange rate regimes in emerging economies (Calvo and Reinhart 2002).

Given the potential importance of unraveling the nature and source of risk this paper empirically analyzes the behaviour of the foreign exchange risk premium for emerging European markets and compares commonalities across countries. While many of these countries are already members of the European Union (EU), they vary in the degree of economic development, integration and progress to membership of the European single currency union, the euro zone. The reduction in exchange rate uncertainty, particularly among member countries, is one motivation for a candidate country to join the euro zone (see Darby et al. 1999 and Byrne and Davis 2005).

This paper's main innovation is to decompose the foreign exchange risk premium in emerging market economies into the common and idiosyncratic (country-specific) components and identify economic factors influencing the common factor. The idiosyncratic component of the risk premium is unique to each country and therefore likely explains the heterogeneity in the risk premium across countries. If the country-specific component in the risk premium is relatively smaller than the common component, it follows that a country may have less opportunity to control the overall risk premium by itself.

On the other hand, the common factor is the risk premium prevailing among a group of countries and may be significant since most countries selected for this study are already members of the EU and their economies influence each other through international trade, financial integration and immigration. Furthermore, in our research setting, the US is the benchmark country and thus her economic and financial developments may become exogenous shocks common to the emerging markets. Using a vector autoregression model and theoretical general equilibrium modeling, Uribe and Yue (2006) identified that the US interest rate impacts upon interest rate spreads in emerging market economies, which consequently have real effects in these economies. Neumeyer and Perri (2005) propose that monetary conditions in emerging economies are dependent upon US interest rates and international factors drive country risk in emerging market economies. Thus monetary conditions in the US would appear to be important for 
emerging market economies. It should be noted that the significant size of the common component may also become a measure of economic and financial integration because it likely indicates that the economy is highly open to other countries.

For this purpose, we employ the nonstationary panel econometric approach of Bai and $\mathrm{Ng}$ (2004) which pools the time-series data of emerging European countries. This approach enables us to distinguish the common and idiosyncratic foreign exchange risk premiums, and sets this paper apart from previous studies since they often investigated the total risk premium in a univariate (or time-series) context without considering commonalities with other countries (see Section 2). Given that our definition of the exchange risk premium is closely related to international parity conditions, as far as we are aware this is the first study to apply this methodology to the analysis of the Uncovered Interest Rate Parity (UIRP) condition and thus seek to provide additional evidence with respect to the UIRP.

The rest of the paper is organized as follows. Section 2 reviews relevant literature and explains the definition of the exchange risk premium employed in this study. Section 3 describes our data set and conducts preliminary analysis. The decomposition of the risk premium into common and idiosyncratic components is carried out in Section 4 using the recently developed nonstationary panel econometric approach (Bai and $\mathrm{Ng} 2004$ ). This section also analyzes economic factors influencing the common factor of the risk premium. Finally, our main findings are summarized in Section 5.

\section{The Exchange Risk Premium Literature Review}

The definition of the exchange risk premium may differ somewhat depending on the researcher. In the absence of data on the forward exchange rate and survey-based expectations on the exchange rate, we derive the exchange risk premium using the UIRP condition. ${ }^{1}$ In this section, we shall explain the risk premium focusing on the statistical characteristics of the premium.

Let us begin with the Covered Interest Rate Parity (CIRP) condition, a longstanding and venerable concept in international finance. The CIRP utilizes the forward market which provides investors with an opportunity to hedge against risks of currency fluctuations. Because hedging risks is important for traders in flexible exchange rate regimes, much research has been conducted using industrial countries and equation (1) below, particularly since the breakdown of the fixed exchange rate regime in the early 1970s.

\footnotetext{
${ }^{1}$ See Isard (1992).
} 
$1+i_{t}=\left(1+i_{t} *\right) F_{t}^{k} / S_{t}$

where $F_{t}^{k}$ and $S_{t}$ are the spot and $k$ th period forward exchange rates at time $t$, whilst $i_{t}$ and $i_{t} *$ are the domestic and foreign interest rates respectively. ${ }^{2}$ Thus, according to the CIRP, the forward premium, which is the difference between the forward and spot rates, is explained by the interest rate differential.

What happens when the foreign exchange rate risk is not covered? This leads us to the concept of the UIRP hypothesis. The UIRP shows that the risk-neutral investor is indifferent to investing in identical financial assets except for currency denomination, and such a relationship can be summarized as follows:

$1+i_{t}=\left(1+i_{t}^{*}\right) E_{t} S_{t+k} / S_{t}$

Here the forward rate in equation (1) is replaced with the expected spot rate, $E_{t} S_{t+k}$, which is the expected value of the spot exchange rate at time $t+k$ given the information available at time $t$. Expressing this equation in $\log$ form, $\ln \left(S_{t}\right)=s_{t}$, where $E_{t} \Delta s_{t+k}$ is the expected change in the spot rate, and ignoring Jensen's inequality term, we have:

$i_{t}-i_{t} *-E_{t} \Delta s_{t+k}=0$

When equation (3) holds, the asset portfolio is in equilibrium, but this condition may not hold due to deviations from UIRP.

Indeed, there is mixed evidence on the UIRP: see Lewis 1995, Engle 1996, Chinn 2006, Carriero (2006). One pervasive explanation of the failure of this relationship is the existence of a risk premium and risk averse investors. Frankel (1982) was an early attempt to model risk in the foreign exchange market using an extended static capital asset pricing model (CAPM). ${ }^{3}$ More recently, Carriero (2006) finds evidence of a stationary but time varying risk premium between the UK and the US when testing UIRP. In contrast, evidence in Bansal and Dahlquist (2000) suggests that the UIRP relationship fails mainly for developed economies. The UIRP holds to a greater extent for countries with a lower per capita income, higher inflation uncertainty and lower credit ratings. In related literature Frankel and Poonalwala (2006) find evidence that the forward exchange rate is a less biased predictor of future spot rates in emerging

\footnotetext{
${ }^{2}$ In this study the exchange rate is defined as domestic currency units per unit of foreign currency. The US is the foreign country hence an asterisk denotes US interest rates.

3 Cochrane and Piazzesi (2005) identify a time-varying risk premium in the bond market using a single factor model which also has information useful for predicting bond excess returns using oneto five-year maturity bonds.
} 
countries compared to industrial countries. ${ }^{4}$ Furthermore, some evidence is obtained that the UIRP tends to hold with longer maturity returns (Flood and Taylor 1997, Meredith and Chinn 1998, and Chinn 2006) although such long maturity assets are often not available in emerging markets. Finally, Bekaert et al. (2007) suggest that evidence against the UIRP is mixed and depends upon the currency. Given this suggestion, this paper seeks to examine the nature of the risk premium in emerging market economies.

In that case, equation (4) may be more useful.

$r p_{t}^{k}=E_{t} \Delta s_{t+k}-i_{t}+i_{t}^{*}$

In equation (4) $r p_{t}{ }^{k}$ measures the deviation from the UIRP. If $r p_{t}{ }^{k}<0$, the home country experiences capital inflow. On the other hand, if $r p_{t}{ }^{k}>0$, the home country faces capital outflow. Thus, deviation from the UIRP is often used to measure international capital mobility or capital market integration across countries (see Obstfeld and Taylor 2004). The most common explanation of the deviation from the UIRP is the time-varying risk premium that separates the spot and forward rates. Other factors contributing to the UIRP violation may include political risk, default risk, differential tax risk and market liquidity — which make financial assets in two countries imperfect substitutes (Hallwood and MacDonald 2000).

Since the expected value of exchange rate changes is unobservable, previous studies have transformed equation (4) to account for this problem as follows:

$r i s k_{t}=r p_{t}^{k}-\varepsilon_{t}=s_{t+k}-s_{t}-i_{t}+i_{t}^{*}$

where $\varepsilon_{t}$ is an expectations error $\left(\varepsilon_{t}=E_{t} s_{t+k}-s_{t+k}\right)$ which follows a white noise process $\left(\varepsilon_{t} \sim \operatorname{iid}(0, \sigma)\right)$ when the investors form rational expectations. In the absence of data on the forward exchange rate and survey-based expected exchange rate in most emerging markets, we will employ equation (5) and use $\left(r p_{t}{ }^{k}-\varepsilon_{t}\right)$ as a proxy for the foreign risk premium.

One may expect that our proxy for the foreign risk premium follows a stationary process since there is mounting evidence of a stationary risk premium. For example, using the data of industrial countries, Taylor (1987) and Carriero (2006) show that a combination of the expected exchange rate change and the interest rate differential yields a stationary time-varying risk premium. Furthermore, Kasman et al. (2008) provide evidence of stationary interest rate differentials between Germany and emerging

\footnotetext{
${ }^{4}$ See also the discussion in Chinn (2006).
} 
markets such as Croatia, Estonia and Turkey. While the stationarity of interest rate spreads does not ensure the stationary premium, this becomes evidence of the high level of financial market integration.

\section{Data and Preliminary Study}

The data used in this paper are obtained from the International Monetary Fund's International Financial Statistics (IFS) for the sample period: January 1998 to August 2010. This sample period is determined by data availability, and monthly frequency is chosen since lower frequency data (i.e., quarterly and annual data) provides us with a smaller number of observations to conduct the univariate (or time-series) analysis of the common factor. Our data set includes the following emerging European economies: Bulgaria, Croatia, Czech Republic, Estonia, Latvia, Lithuania, Romania, Russia, Slovenia, Turkey and Ukraine. ${ }^{5}$ The composition of our group of countries is a unique aspect of this research.

Many emerging economies in this study only recently became EU members, and incidentally, these countries changed their exchange rate regimes during our sample period. ${ }^{6}$ For example, Bulgaria adopted a floating exchange regime (1990-1997) and shifted to a currency board arrangement. Estonia, Latvia, and Lithuania had fixed their exchange rate, but when the euro was introduced, these countries fixed their exchange rate against the euro with the exception of Latvia whose exchange rate was fixed against the SDR. Similarly, Slovenia joined the euro area in 2007 abandoning a floating exchange rate regime. Among the other countries, the Czech Republic adopted intermediate exchange rate regime until 1997 and shifted to a floating regime thereafter. Croatia's exchange rate regime is also categorized as an intermediate regime. Ukraine's rate was pegged to the US dollar, but became increasingly flexible since 1999. Due to the regular interventions however, the regime is classified as a conventional pegged arrangement from 2001. There are countries that have not changed their exchange rate regime during our sample period, which include Russia, Romania and Turkey that employ floating exchange rate regimes.

We utilize monthly data on market interest rates and the bilateral exchange rates

\footnotetext{
5 The Czech Republic, Estonia, Latvia, Lithuania, and Slovenia became EU members in 2004, and Bulgaria and Romania joined in 2007. Non-members, Croatia and Turkey initiated negotiation in 2005 for EU accession. We remove significant outliers for Russia for 1998M9, for Turkey 2000M12 and 2001M2 and 1998M8 for the Ukraine.

${ }^{6}$ The IMF provides detailed classification of exchange rate regimes on its homepage (http://www.imf.org).
} 
(defined as end of period domestic currency units per unit of US dollar) (AA..ZF). Since the market for long-term government securities is typically illiquid in emerging markets, interest rates are short-term money market rates (60..ZF). ${ }^{7}$ Interest rates and exchange rate changes are expressed in annual percentages. Based on equation (5), we derive the risk premium ( $\left.r i s k_{i t}\right)$ in a panel data set for country $i$ and time $t$ as follows.

$$
\text { risk }_{i t}=\left(s_{i t+1}-s_{i t}\right)-i_{i t}+i_{t}^{*}, \quad i=1, \ldots, 11, t=1998 \mathrm{M} 1, \ldots, 20010 \mathrm{M} 8
$$

The asterisk indicates the benchmark country which is the US in this study. As mentioned in the previous section, our definition of risk $k_{i t}$ includes the expectations error of investors, and the long-run UIRP requires risk $k_{i t}$ to be stationary.

Table 1 provides the basic statistical summary of our foreign exchange risk premiums and their components; exchange rate changes $\left(\Delta s_{i t+1}=s_{i t+1}-s_{i t}\right)$ and interest rate differentials $\left(i_{i t}-i_{t}{ }^{*}\right)$. This table indicates that the mean and standard deviation of the bilateral dollar exchange rates differ according to the country. More than half of our countries have negative average exchange rate growth, hence they experienced currency appreciation (revaluation) during our sample period. We note that the level of currency appreciation (revaluation) differs substantially among countries, with a range of one to 20 percent per year. In contrast, some countries (Romania, Russia and Ukraine) experienced currency depreciation (devaluation). Those three countries also experienced higher exchange rate volatility, measured by standard deviation.

Interest rate differentials are positive in nine out of the 11 countries. According to our definition of interest rate differentials $\left(i_{i t}-i_{t}{ }^{*}\right)$, their typically positive value suggests relatively higher interest rates in emerging markets compared with the US rate. The interest rates of Romania, Turkey, and Ukraine were considerably higher than the benchmark rate. Those countries also experienced high volatility in interest rates, which reflects their economic and financial difficulties during our sample period. The interest rate spread and US interest rate are plotted in Figures 1 and 2. Clearly there is a high degree of commonality in interest rate spreads and this would appear, at least graphically, to be related to the US rate.

Table 1 also shows that the risk premium is negative on average in all countries. Appreciating currencies and high interest rates in emerging markets attribute to this negative risk premium. Not surprisingly, countries experienced high volatility in

\footnotetext{
${ }^{7}$ Estonia has missing data in 1999M3 and 1999M10 to M12 which are created by linear interpolation.
} 
exchange rates and interest rates tend to exhibit high volatility in the risk premium. Furthermore, using univariate unit root tests the premium is almost always found to be stationary. Table 2 presents evidence for ADF and ADF-GLS tests the null hypothesis of unit root is typically rejected. We consider this time series as preliminary and indicative, which we investigate further using more advanced panel time series methods that are considered to have superior statistical properties.

A preliminary analysis is also conducted to examine if the UIRP holds for a pooled regression (see Figure 3). Essentially, this sets out a scatter plot illustrating the bivariate relationship between the annualized percentage change in the exchange rate $\left(\Delta s_{i t+1}\right)$ and interest rate differential $\left(i_{i t}-i_{t} *\right)$. This indicates that the interest rate differential is not especially related to exchange rate changes, in contrast to the UIRP, and the estimated coefficient is significantly different from one, suggesting a possible violation of the UIRP. $^{8}$

\section{The Decomposition of the Exchange Risk Premium}

Previous studies rarely attempted to decompose the risk premium into common and idiosyncratic components although their research target was industrial countries which can be characterized as open economies. If there is a degree of cross correlation in any panel and one is interested in the time-series properties of this data, then it is sensible to consider their stationary properties.

For this purpose, we employ the PANIC approach (Bai and $\mathrm{Ng}$, 2004). This method utilizes a factor structure to model the nature of the nonstationarity in large dimensional panels. This is set out for the case where an intercept is included:

risk $_{i t}=c_{i}+\Lambda_{i}^{\prime} F_{t}+e_{i t}$

The series risk $k_{i t}$ is a sum of a cross-section specific constant $\left(c_{i}\right)$, a common component $\Lambda_{i}{ }^{\prime} F_{t}$, where $\Lambda_{i}$ is a corresponding matrix of factor loadings and $F_{t}$ are the factors, and

\footnotetext{
${ }^{8}$ The pooled estimated regression suggested the estimated coefficient on interest rate differentials in the UIRP regression was -0.09 (t-statistic $=1.54$ ), hence this is significantly different from one, and represents a failure of UIRP although not to the extent suggested in the survey by Froot and Thaler (1990). A preliminary analysis indicated a substantial proportion of the bivariate correlations using $\mathrm{Ng}$ (2006) and that these were insignificantly different from zero. Furthermore, a comparison of the standard deviation of the idiosyncratic to the data indicated that a substantial proportion of the variability of Romania, Russia, Turkey and the Ukraine was explained by the idiosyncratic component. This suggests that a common factor is more likely to exist for $N=7$ which is also consistent with an increase in the eigenvalue of this smaller panel of countries.
} 
an error, $e_{i t}$, which is the idiosyncratic component. The panel time series risk $k_{i t}$ is nonstationary if the common factors or the idiosyncratic component, or both, are nonstationary. In this connection, the PANIC allows us to identify whether nonstationarity is pervasive or series-specific. Bai and $\mathrm{Ng}$ (2004) propose the method of principle components to obtain the common factors, and the appropriate number of factors is determined by the information criteria developed by Bai and $\mathrm{Ng}$ (2002). The PANIC does not assume that only the idiosyncratic component may be nonstationary, unlike Moon and Perron (2004) and Pesaran (2006). The PANIC determines explicitly whether the nonstationarity in a panel time series is pervasive or variable-specific.

We make use of two test statistics from Bai and Ng (2004): an Augmented Dickey Fuller (ADF) test on the common factor $\left(A D F_{\hat{F}}^{c}\right)$ and a Fisher-type pooled ADF test on the idiosyncratic individual errors $\left(A D F_{\hat{e}}^{c}(i)\right)$. The test statistic on the idiosyncratic element is distributed as standard normal as follows:

$$
P_{\hat{e}}^{c}=\frac{-2 \sum_{i=1}^{N} \log p(i)-2 N}{\sqrt{4 N}} \rightarrow \mathrm{N}(0,1) .
$$

where $p(i)$ is the $p$-value associated with $\left(A D F_{\hat{e}}^{c}(i)\right)$ of the ADF test for the $i$ cross section, and $\rho_{i}$ is the autoregressive parameter of the independent error processes. The test statistic examines whether $\mathrm{H}_{0}: \rho_{i}=1 \quad \forall i$ against $\mathrm{H}_{1}: \rho_{i}<1$ for some $i$. Thus, under the null hypothesis, all cross-sections are nonstationary and the alternative is that some may be stationary.

The stationarity of the common factors is individually examined using the ADF test. With one common factor, this test becomes identical to the original ADF test. Thus, this test is based on the following specification with the null of $\theta=0$ against the alternative of $\theta<0$.

$$
\Delta \hat{F}_{t}=\alpha+\theta \hat{F}_{t-1}+\delta_{i} \sum_{i=1}^{p} \hat{F}_{t-i}+\varepsilon_{t}
$$

where $\hat{F}_{t}$ is the estimate of common factors. 
The PANIC results are summarized in Table 3. In order to see the robustness of our findings, we conduct a panel data analysis for the full-sample $(N=11)$ and sub-sample of countries $(N=7)$ which excludes four countries (Romania, Russia, Turkey and Ukraine) with high volatility in both exchange rates and interest rates. The analysis is conducted using the US as a benchmark and then Germany in order to check the robustness of our finding.

First, this table shows three information criteria (IC1 to IC3) to determine the number of common factors in our data. ${ }^{9}$ These information criteria produce somewhat mixed results. While two criteria (IC1 and IC2) suggest five common factors, one criterion (IC3) raises evidence of one common factor for the US. The subsequent part of our analysis is based on this criterion and thus one factor since although the first two criteria may be more reliable in a large data set (i.e., large $N$ and $T$ ), they tend to overestimate the number of true common factors in a finite sample context (Bai and $\mathrm{Ng} 2002$ ).

Table 3 shows the common factor is stationary (i.e. $\left.A D F_{\hat{F}}^{c}<-2.86\right)$ and the idiosyncratic is stationary (i.e. $P_{\hat{e}}^{c}>1.64$ ). This result remains valid even when the abovementioned four countries are excluded from the eleven country analysis. This also implies that the exchange risk premium is stationary for these countries, and indicates the UIRP holds in the long-run. There are several occurrences of economic and financial turbulence during our sample period (e.g., changes in exchange rate regimes, the sub-prime loan problem and Greek debt crisis), but stability tests (Andrews-Ploberger (A-P) and Andrews-Quandt (A-Q)) suggest that the common factor estimated from a panel of eleven countries is stable over time (Table 4). Indeed, given that we find evidence of a stationary risk premium and structural breaks are frequently cited as leading to evidence of nonstationarity (e.g., Perron 1989), breaks are expected to have only a limited effect on the Bai-Ng test results. ${ }^{10}$

\footnotetext{
${ }^{9}$ There three information criteria are from Bai and $\mathrm{Ng}(2002)$. Where $\hat{\sigma}^{2}(k)$ is based on the residuals from a regression of the first differenced data on $k$ principal components, the first information criterion can be expressed as $I C_{1}(k)=\ln \hat{\sigma}^{2}(k)+k \ln (N T /(N+T))(N+T / N T)$. The second information criterion is $I C_{2}(k)=\ln \hat{\sigma}^{2}(k)+k \ln (N+T / N T) \ln [\min \{\sqrt{N}, \sqrt{T}\}]^{2}$. Bai and $\mathrm{Ng}$ (2002) however suggest that a third information criterion is to be preferred with panel cross sectional correlation: $I C_{3}(k)=\ln \hat{\sigma}^{2}(k)+k \hat{\sigma}^{2}(N-T-k) \ln (N T) / N T$.

10 One alternative is to develop an estimator for the common factors and information criteria that identifies the number of common factors in panel estimation and which also take account of structural breaks. There are several ways to test for regime shifts in panel data, but they usually
} 
In order to check the sensitivity of the result to the benchmark currency, the analysis is replicated for our group of eleven countries using Germany as a benchmark. According the third information criterion (i.e., IC3), we fail to find evidence of a common factor (see Table 3). This would suggest that for this large sample of emerging market economies, the US is the dominant country with respect to a risk premium. Similarly, when we consider the sample of seven countries, we do not find evidence of a common factor either. Thus, the subsequent analysis on the common factor focuses on the data set with the US as the benchmark.

Furthermore, we examine in Table 5 the relative importance of the common factor using two statistical ratios: firstly, the ratio of the standard deviation of the idiosyncratic residual in equation (7) to the differenced risk data (i.e. $\left.\sigma\left(\Delta e_{i t}\right) / \sigma\left(\Delta r i s k_{i t}\right)\right)$ and secondly the ratio of the standard deviation of the common to the idiosyncratic component (i.e. $\left.\sigma\left(\Lambda_{i}{ }^{\prime} F_{t}\right) / \sigma\left(e_{i t}\right)\right)$. The former should be equal to one and the latter equal to zero if the idiosyncratic dominates. According to $\sigma\left(\Lambda_{i}{ }^{\prime} F_{t}\right) / \sigma\left(e_{i t}\right)$, the common component of the risk premium is relatively high in Bulgaria, Estonia, and Slovenia in the eleven country analysis. In contrast, the idiosyncratic dominates the variation of the risk premium in Ukraine. This is confirmed by the ratio of the standard deviation of the idiosyncratic component to the differenced data (i.e. $\left.\sigma\left(\Delta e_{i t}\right) / \sigma\left(\Delta r i s k_{i t}\right)\right)$.

The seven country analysis yields a very similar outcome (Table 5), but we can see more clear characteristics of the risk premium. The risk premium of Bulgaria, Estonia and Slovenia are dominated by the common factor, which suggests the sensitivity of these countries to economic and financial changes in foreign countries. By contrast, of the seven countries, Lithuania with the highest $\sigma\left(\Delta e_{i t}\right) / \sigma\left(\Delta r i s k_{i t}\right)$ and the lowest $\sigma\left(\Lambda_{i}{ }^{\prime} F_{t}\right) / \sigma\left(e_{i t}\right)$ appears to have a significant country-specific element in her risk premium and shocks are temporary to her risk premium. This may be an indication that large economies tend to have more influence on their own risk premium.

In terms of associating the pervasive risk premium with potential determinants, we estimate the relationship between the common factor and both US inflation and industrial production using the OLS. We chose these explanatory variables based on a Taylor-type monetary policy rule and our data frequency (i.e., monthly data). Additionally, Uribe and Yue (2006) demonstrate that the US interest rate explains about no such assumptions, it is difficult to incorporate shift effects during the estimation of common factors. 
20 percent of variation in economic activity in emerging markets. ${ }^{11}$ Data on the CPI and industrial production are obtained from the IFS, and annual growth is calculated for each variable. Our results are reported in Table 6 and confirm that US inflation is significant at the one percent significance level in explaining the common risk factor. We identify a negative relationship and increases in inflation are associated with a more than proportionate change in risk. ${ }^{12}$ This is consistent with US monetary policy explaining a degree of the risk premium for emerging market economies. In contrast to the US inflation, industrial production is found to be insignificant in our data. Overall this should reflect the inflation preoccupation of the US monetary authorities during our sample period.

Furthermore, the parameter stability test suggests that most explanatory variables are invariant over time. Two structural break tests support parameter stability for inflation and the production (Table 6). However, there is some (weak) evidence of instability in the constant term in their relationship. Since no evidence of a break is obtained from the common factor, this finding may attributable to instability in our explanatory variables. Furthermore, the timing of this shift coincides more or less with that of the sub-prime loan problem; the failure of Lehman Brothers in September 2008 seems to have effects on this relationship. This leads us to the application of a regime-shift model.

Here, a two-regime Markov-switching model which allows a shift in the mean and variance is implemented to analyze the relationship between the common factor and explanatory variables. Our result in Table 7 suggests that first of all there is indeed a structural break in our common factor model. The likelihood ratio (LR) test provides evidence of a strong nonlinearity in our model. Furthermore, most observations are included in Regime 1 rather than Regime 0. Since Figure 4 suggests that Regime 1 corresponds to the post-Lehman shock period, it appears that many countries have experienced a sudden shock, i.e., an increase in the average of risks, around the time of the Lehman shock. Indeed our estimate for the constant increases (more than three times) in the absolute terms after the occurrence of this crisis.

\section{Conclusion}

This paper empirically analyzed the foreign exchange risk premium of eleven emerging

\footnotetext{
${ }^{11}$ The significance of US monetary policy also chimes with difficulties for Mexican debt in the early 1980s and consequently a heightened sense of risk due to a contractionary monetary policy. 12 There is unlikely to be any endogeneity between emerging economies risk and US monetary policy responses.
} 
European countries. Unlike most previous research, the time-varying premium here is decomposed into common and idiosyncratic factors using the statistical method developed by Bai and $\mathrm{Ng}$ (2004). This is a rather different approach to investigating the foreign exchange risk premium because most previous research does not consider any cross-sectional element in the premium. Furthermore, the risk premium of emerging countries in Europe has not been much studied although exchange rate risk is one important concern for most countries considering adopting the euro.

Our results suggest that, like industrial countries, the foreign exchange premium in emerging markets is stationary. Furthermore, the idiosyncratic component of the premium is found to be stationary. This gives rise to evidence consistent with the UIRP in the long-run context, and thus it follows that the UIRP can be viewed as an equilibrium concept. Furthermore, we analyzed what economic factors can explain the common risk premium for these countries. Our results show that this common factor in emerging markets reflects economic and financial developments in the US. In particular, US inflation has explanatory power over the common movement in the premiums. This confirms that emerging markets are heavily sensitive to the US monetary policy, consistent with Uribe and Yue (2006) and Neumeyer and Perri (2006). Our work is in line with the perspective that theoretical models of the foreign exchange market should incorporate an important role for risk premium, for examples see Duarte and Stockman (2005) and Engle and West (2006). Our work also highlights the importance of the Global Financial Crisis for empirical modeling, since the greater volatility has consequences for nature of violations of UIRP. 


\section{References}

Andrews, Donald W. K. and Werner Ploberger, 1994. Optimal Tests When a Nuisance Parameter is Present Only Under the Alternative, Econometrica Vol. 62, No. 6, pp 1383-1414.

Bai, Jushan and Serena Ng, 2002. Determining the number of factors in approximate factor models, Econometrica Vol. 70, No. 1, pp. 191-221.

Bai, Jushan and Serena Ng, 2004. A panic attack on unit roots and cointegration, Econometrica Vol. 72, No. 4, pp. 1127-1177.

Bansal, Ravi and Magnus Dahlquist, 2000. The forward premium puzzle: Different tales from developed and emerging economies, Journal of International Economics Vol. 51, No. 1, pp. 115-144.

Bekaert, Geert, Min Wei and Yuhang Xing 2007. Uncovered Interest Rate Parity and the Term Structure, Journal of International Money and Finance Vol. 26, No. 6, pp. 1038-1069.

Byrne, Joseph P. and E. Philip Davis, 2005. Investment and uncertainty in the G7, Review of World Economics, Vol. 141, No. 1, pp. 1-32.

Calvo, Guillermo A. and Carmen M. Reinhart, 2002. Fear of floating, The Quarterly Journal of Economics, Vol. 117, No. 2, pp. 379-408.

Carriero, Andrea, 2006. Explaining US-UK interest rate differentials: a reassessment of the uncovered interest rate parity in a Bayesian framework, Oxford Bulletin of Economics and Statistics Vol. 68, No. s1, pp. 879-899.

Chinn, Menzie D., 2006. The (partial) rehabilitation of interest rate parity in the floating rate era: longer horizons, alternative expectations, and emerging markets, Journal of International Money and Finance Vol. 25, No. 1, pp. 7-21.

Cochrane, John H. and Monika Piazzesi, 2005. Bond risk premia, American Economic Review Vol. 95, No. 1, pp. 138-160.

Darby, Julia, Andrew Hughes Hallett, Jonathan Ireland and Laura Piscitelli, 1999. The impact of exchange rate uncertainty on the level of investment, Economic Journal, Vol. 109, No. 454, pp. C55-67.

Elliott, Graham, Thomas J. Rothenberg and James H. Stock, 1996. Efficient tests for an autoregressive unit root, Econometrica, Vol. 64, No. 4, pp. 813-36.

Engle, Charles, 1996. The forward discount anomaly and the risk premium: a survey of recent evidence, Journal of Empirical Finance Vol. 3, No. 2, pp. 123-192.

Flood, Robert P. and Mark P. Taylor, 1996. Exchange rate economics: What is wrong with the conventional macro approach? In Frankel, J.A., Galli, G., Giovannini, A. Eds., 
Micro Structure of Foreign Exchange Markets. University of Chicago Press.

Frankel, Jeffrey A., 1982. In search of the exchange risk premium: A six-currency test assuming mean-variance optimization, Journal of International Money and Finance, Vol. 1, No. 1, pp. 255-274.

Frankel, Jeffrey and Jumana Poonawala, 2006. The Forward Market in Emerging Currencies: Less Biased than in Major Currencies. NBER Working Paper No. 12496.

Froot, Kenneth A. and Richard H. Thaler, 1990. Foreign Exchange, Journal of Economic Perspectives, Vol. 4, No. 3, pp. 179-92.

Hallwood, C. Paul and Ronald MacDonald, 2000. International Money and Finance, $3^{\text {rd }}$ Edition, Blackwell, Oxford.

Hansen, Bruce E., 1997. Approximate asymptotic p-values for structural change tests, Journal of Business and Economic Statistics, pp 60-67.

Isard, Peter, 1992. Uncovered interest parity. In John Eatwell, Murray Millgate, and Peter Newman (eds.), The New Palgrave Dictionary of Money and Finance. Macmillan, London.

Kasman, Adnan, Saadet Kirbas-Kasman and Evrim Turgutlu, 2008. Monetary policy convergence of potential EMU accession countries: A cointegration analysis with shifting regimes, Economic Modelling, Vol. 25, No. 2, pp. 340-350.

Lewis, Karen K., 1995. Puzzles in international financial markets. In G. Grossman and K. Rogoff. Ed. Handbook of International Economics, Vol. 3, Elsevier North Holland. Mehl, Arnaud and Lorenzo Cappiello, 2007. Uncovered interest parity at distant horizons: evidence on emerging economies and nonlinearities, Working Paper Series No. 801, European Central Bank.

Meredith, Guy and Menzie D. Chinn, 1998. Long-Horizon Uncovered Interest Rate Parity, NBER Working Papers No. 6797.

Moon, Hyungsik.R. and Benoit Perron, 2004. Testing for a unit root in panels with dynamic factors, Journal of Econometrics, Vol. 122. No. 1, pp. 81-126.

Neumeyer, Pablo A. and Fabrizio Perri, 2005. Business cycles in emerging economies: the role of interest rates, Journal of Monetary Economics, Vol. 52, No. 2, pp. 345-380.

$\mathrm{Ng}$, Serena, 2006. Testing Cross-Section Correlation in Panel Data using Spacings. Journal of Business and Economics Statistics, Vol. 24, No. 1, pp. 12-23.

Obstfeld, Maurice and Alan M. Taylor, 2004. Global Capital Markets: Integration, Crisis and Growth. Cambridge University Press, New York.

Pesaran, M. Hashem, 2007. A simple panel unit root test in the presence of cross-section dependence, Journal of Applied Econometrics, Vol. 22, No. 2, pp. 265-312.

Phillips, P.C.B. and B.E. Hansen, 1990. Statistical inference in instrumental variable 
regression with $I(1)$ processes, Review of Economic Studies, Vol. 57, No. 1, pp. 99-125.

Stock, James H. and Mark W. Watson, 2007. Why has U.S. inflation become harder to forecast? Journal of Money Credit and Banking, Vol. 39, No. 1, pp. 3-33.

Taylor, Mark P., 1987. Risk premia and foreign exchange: a multiple time series approach to testing uncovered interest-rate parity, Weltwirtschaftliches Archiv, Vol. 123, No. 4, pp. 579-91.

Uribe, Martin and Vivian Z. Yue (2006) Country spreads and emerging countries: Who drives whom? Journal of International Economics, Vol. 69, No. 1, pp. 6-36. 


\section{TABLES}

Table 1. Risk Premium, Exchange Rate and Interest Differential Summary Statistics

\begin{tabular}{||l|c|c|c|c|c|c||}
\hline \multirow{2}{*}{ Country } & \multicolumn{2}{|c|}{ Risk Premium } & Exchange Rate Change & \multicolumn{2}{c|}{$\begin{array}{c}\text { Interest Rate } \\
\text { Differential }\end{array}$} \\
\cline { 2 - 7 } & Mean & $\begin{array}{c}\text { Standard } \\
\text { Deviation }\end{array}$ & Mean & $\begin{array}{c}\text { Standard } \\
\text { Deviation }\end{array}$ & Mean & $\begin{array}{c}\text { Standard } \\
\text { Deviation }\end{array}$ \\
\hline Bulgaria & -1.42 & 38.25 & -1.84 & 38.11 & -0.42 & 2.13 \\
\hline Croatia & -3.54 & 37.28 & -1.43 & 37.07 & 2.11 & 3.71 \\
\hline Czech Republic & -6.38 & 46.56 & -5.23 & 46.48 & 1.14 & 2.89 \\
\hline Estonia & -3.56 & 37.75 & -1.92 & 37.67 & 1.64 & 2.91 \\
\hline Latvia & -1.53 & 28.31 & -1.53 & 28.31 & 0.46 & 2.68 \\
\hline Lithuania & -3.50 & 30.28 & -3.60 & 30.35 & -0.10 & 1.63 \\
\hline Romania & -15.26 & 42.48 & 10.52 & 43.42 & 25.78 & 27.69 \\
\hline Russia & -1.88 & 34.62 & 12.78 & 79.66 & 6.61 & 15.16 \\
\hline Slovenia & -1.42 & 37.51 & -1.42 & 37.51 & 1.56 & 1.87 \\
\hline Turkey & -20.93 & 55.00 & -19.77 & 65.06 & 34.82 & 39.45 \\
\hline Ukraine & -2.94 & 32.05 & 0.20 & 49.29 & 10.94 & 16.61 \\
\hline \hline
\end{tabular}

Notes: The foreign exchange premium is determined by $1200 *\left(s_{i t+1}-s_{i t}\right)-i_{i t}+i_{t} *$. Where $s_{i t}$ is defined as the natural $\log$ of domestic currency units for country $i$ per US dollar, $i_{i t}$ is the domestic interest rate and $i_{t}{ }^{*}$ is the US interest rate. The interest rate differential is defined as $i_{i t}-i_{t} *$ We use money market interest rates. Sample period 1998M1 to 2010M8. 
Table 2. Unit Root Tests of Risk Premium

\begin{tabular}{||l|c|c||}
\hline & ADF-GLS & ADF \\
\hline Bulgaria & $-11.134^{*}$ & $-11.427^{*}$ \\
\hline Croatia & $-11.844^{*}$ & $-12.405^{*}$ \\
\hline Czech Republic & $-3.817^{*}$ & $-11.967^{*}$ \\
\hline Estonia & $-9.762^{*}$ & $-11.451^{*}$ \\
\hline Latvia & $-11.468^{*}$ & $-11.547^{*}$ \\
\hline Lithuania & $-11.420^{*}$ & $-11.420^{*}$ \\
\hline Romania & -1.672 & $-10.378^{*}$ \\
\hline Russia & $-7.843^{*}$ & $-8.000^{*}$ \\
\hline Slovenia & $-10.540^{*}$ & $-11.427^{*}$ \\
\hline Turkey & $-9.236^{*}$ & $-10.364^{*}$ \\
\hline Ukraine & $-3.849^{*}$ & $-8.241^{*}$ \\
\hline
\end{tabular}

Note: The 5\% asymptotic critical value for ADF-GLS is -1.98 from $\mathrm{Ng}$ and Perron (2001), in bold and with asterisk when significant. The ADF test has a 5\% asymptotic critical value of -2.86 from Fuller (1976), with asterisk $(*)$ when statistically significant. Null hypothesis of both tests is unit root. Sample period 1998M1-2010M8. United States is the benchmark country. 
Table 3. PANIC Evidence for the Risk Premium

\begin{tabular}{|c|c|c|c|c|c|}
\hline & $\begin{array}{c}\text { Idiosyncratic } \\
P_{\hat{e}}^{c} \\
\end{array}$ & $\begin{array}{c}\text { Common factor } \\
A D F_{\hat{F}}^{c}\end{array}$ & IC1 & $\overline{I C 2}$ & $\overline{I C 3}$ \\
\hline \multicolumn{6}{|c|}{ United States benchmark } \\
\hline 11 countries & $6.112 *$ & $-4.863 *(63 \%)$ & 5 & 5 & 1 \\
\hline 7 countries & $4.390 *$ & $-3.763 *(87 \%)$ & 5 & 5 & 1 \\
\hline \multicolumn{6}{|c|}{ German benchmark } \\
\hline 11 countries & $6.250 *$ & $-3.655 *(46 \%)$ & 5 & 5 & 0 \\
\hline 7 countries & $3.898 *$ & $-4.176 *(37 \%)$ & 5 & 5 & 0 \\
\hline
\end{tabular}

Notes: Asterisk (*) denotes rejection of the null hypothesis of unit root. In our factor model, $A D F_{\hat{F}}^{c}$, the factor unit root test, has a $5 \%$ asymptotic critical value of -2.86 (see Bai and $\mathrm{Ng}, \mathrm{p} .1135,2004$ ). The idiosyncratic unit root test, $P_{\hat{e}}^{c}$ is distributed as standard normal, hence the critical value at the 5\% level is 1.64 . Lag lengths are determined by the formula $4[\min [N, T] / 100]^{1 / 4}$ following Bai and $\mathrm{Ng}(2004)$. The data set covers eleven countries from 1998M1 to 2010M8. The maximum number of the common factors is equal to five. Four countries, Romania, Russia, Turkey, and Ukraine, are excluded for the seven-country analysis. Eigenvalues in parentheses give an impression of the degree to which the different factors explain overall variation in the panel time series. The US dollar or synthetic German mark is used as a benchmark. 
Table 4. The Stability Test for the Common Factor

\begin{tabular}{||c|c|c|c|c||}
\hline A-Q Test & P-Value & $\begin{array}{c}\text { Possible Break } \\
\text { Date }\end{array}$ & A-P Test & P-Value \\
\hline 3.648 & 0.431 & $2008 \mathrm{M} 5$ & 0.492 & 0.447 \\
\hline
\end{tabular}

Notes: Sample period 1998M1 to 2010M8. The structural break tests are based on and Andrews-Quandt (A-Q) and Andrews-Ploberger (A-P) (see Andrews and Ploberger, 1994). The p-values are obtained using Hansen's method (1997), significant at the $5 \%$ level with an asterisk (*).

Table 5. Further PANIC Evidence for the Risk Premium: Factor Importance

\begin{tabular}{|c|c|c|c|c|}
\hline & \multicolumn{2}{|c|}{11 countries } & \multicolumn{2}{|c|}{7 countries } \\
\hline & $\sigma\left(\Delta e_{i t}\right) / \sigma\left(\Delta r i s k_{i t}\right)$ & $\sigma\left(\Lambda_{i}^{\prime} F_{t}\right) / \sigma\left(e_{i t}\right)$ & $\sigma\left(\Delta e_{i t}\right) / \sigma\left(\Delta r i s k_{i t}\right)$ & $\sigma\left(\Lambda_{i}^{\prime} F_{t}\right) / \sigma\left(e_{i t}\right)$ \\
\hline Bulgaria & 0.083 & 3.367 & 0.064 & 4.277 \\
\hline Croatia & 0.188 & 2.423 & 0.151 & 2.821 \\
\hline Czech Rep & 0.225 & 2.115 & 0.188 & 2.237 \\
\hline Estonia & 0.071 & 3.453 & 0.057 & 4.328 \\
\hline Latvia & 0.163 & 2.268 & 0.179 & 2.240 \\
\hline Lithuania & 0.240 & 1.817 & 0.254 & 1.772 \\
\hline Romania & 0.458 & 1.029 & -- & -- \\
\hline Russia & 0.764 & 0.455 & -- & -- \\
\hline Slovenia & 0.069 & 3.548 & 0.044 & 4.881 \\
\hline Turkey & 0.860 & 0.394 & -- & -- \\
\hline Ukraine & 1.000 & 0.003 & -- & -- \\
\hline
\end{tabular}

Notes: This table is based on PANIC results from Table 3. The quotient $\sigma\left(\Delta e_{i t}\right) / \sigma\left(\Delta r i s k_{i t}\right)$ is the ratio of the standard deviation of the idiosyncratic to the differenced risk data and $\sigma\left(\Lambda_{i}{ }^{\prime} F_{t}\right) / \sigma\left(e_{i t}\right)$ is the ratio of the standard deviation of the common to the idiosyncratic component. The former should be equal to one and the latter equal to zero if the idiosyncratic dominates. Sample period 1998M1-2010M8. 
Table 6. Determinant of the US Common Risk Factor

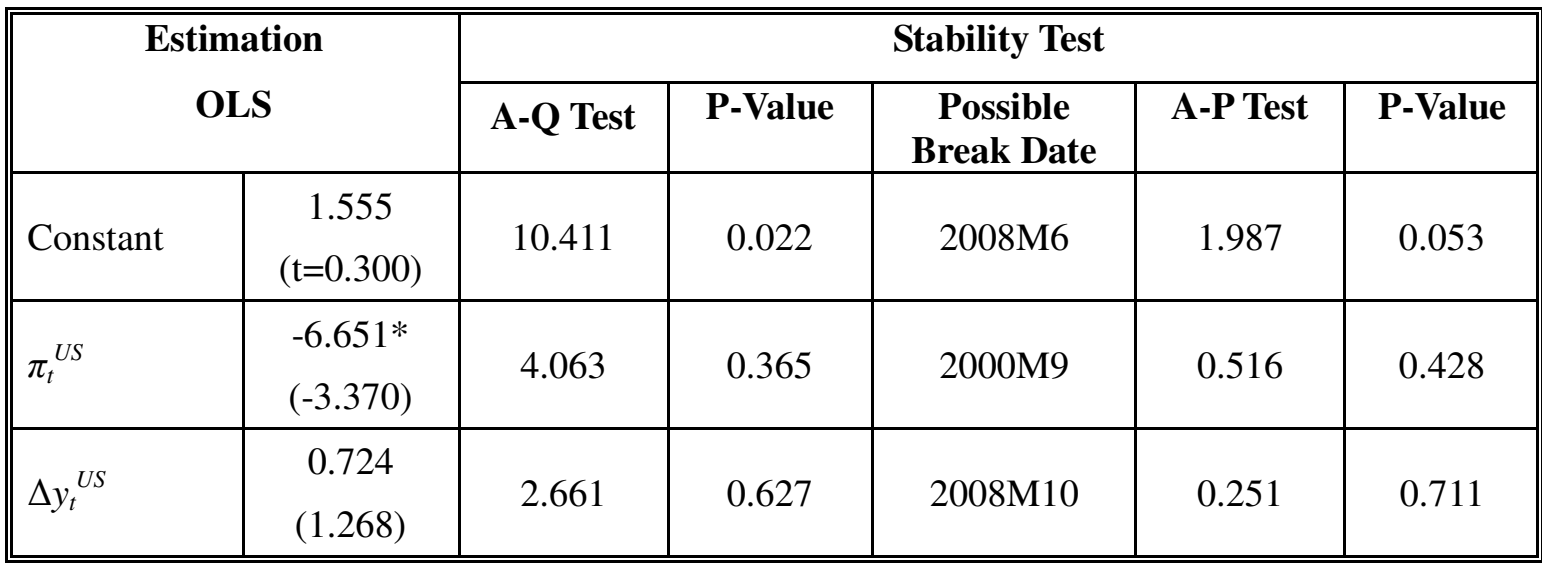

Notes: Sample period 1998M2 to 2010M8. We use OLS, in which the dependent variable is the common factor from the risk premium. Explanatory variables are US Inflation $\left(\pi_{t}^{U S}\right)$ and US industrial production $\left(\Delta y_{t}^{U S}\right)$. Parentheses contain t-statistics: asterisk $(*)$ denotes indicate estimated coefficients statistically significant at the $5 \%$ level. See also Table 4. 
Table 7. Single Equation Regime-Switching

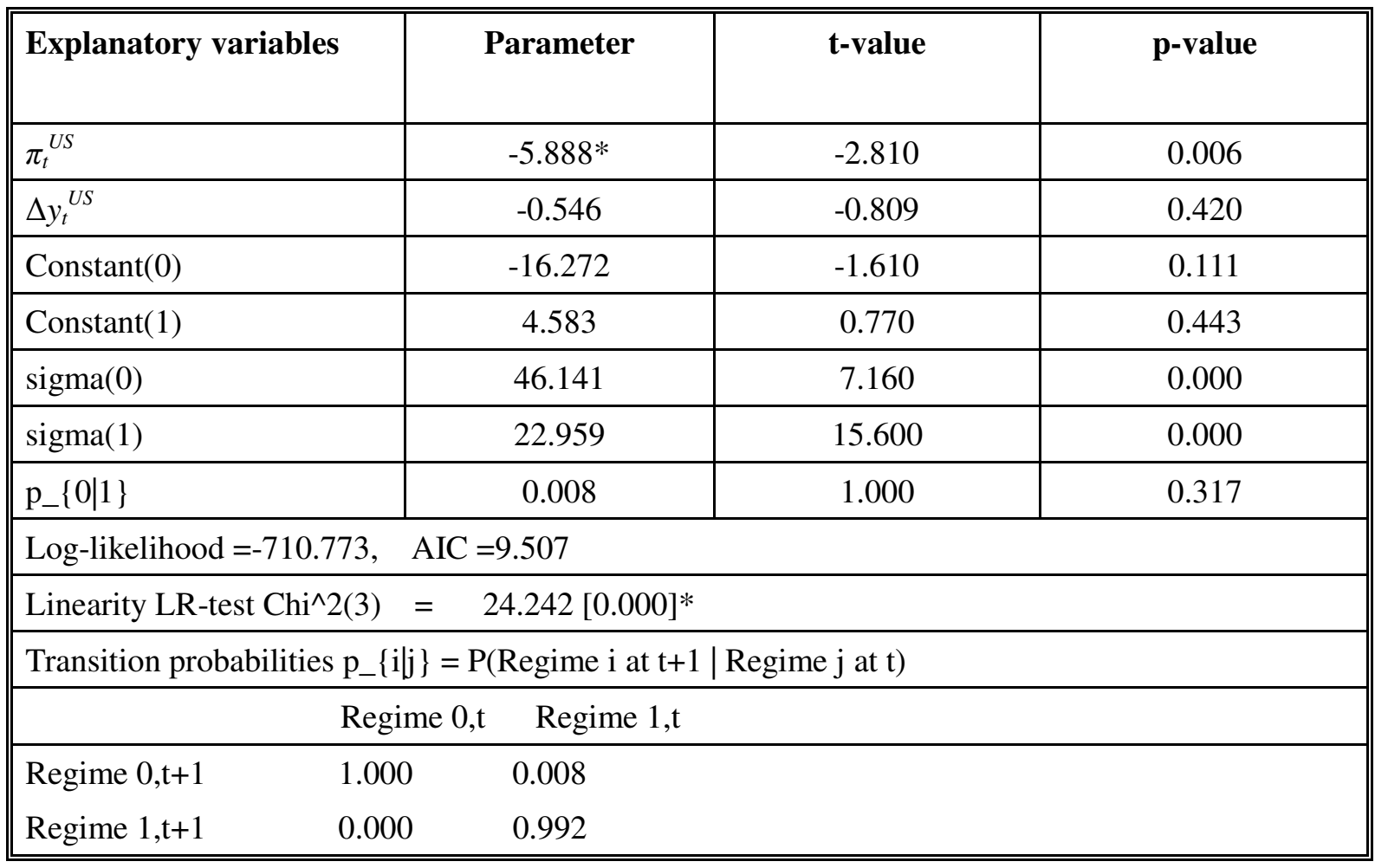

Notes: Dependent variable is risk common factor. Explanatory variables are US Inflation $\left(\pi_{t}^{U S}\right)$ and US industrial production $\left(\Delta y_{t}^{U S}\right)$. Asterisk $(*)$ denotes indicate estimated coefficients statistically significant at the $5 \%$ level, p-values in square brackets. Sample period 1998M1-2010M8. 
Figure 1. Interest Rate Differentials

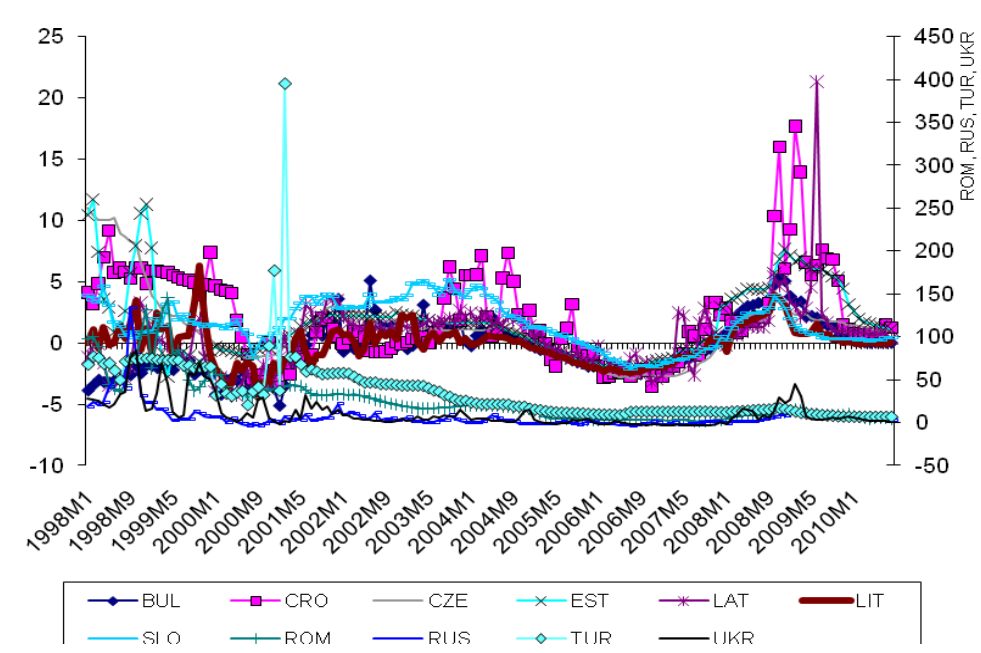

Figure 2. US Interest Rates

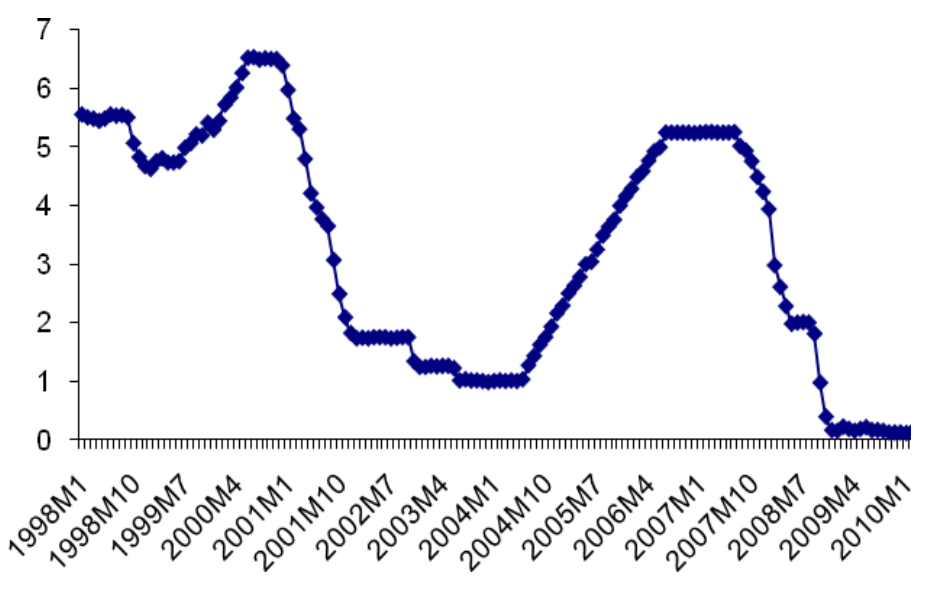

Notes: Bulgaria (BUL), Croatia (CRO), Czech Republic (CZE), Estonia (EST), Latvia (LAT), Lithuania (LIT), Romania (ROM), Russia (RUS), Slovenia (SLO), Turkey (TUR), and Ukraine (UKR).

\section{Figure 3. Exchange Rate and Interest Rate Relation}

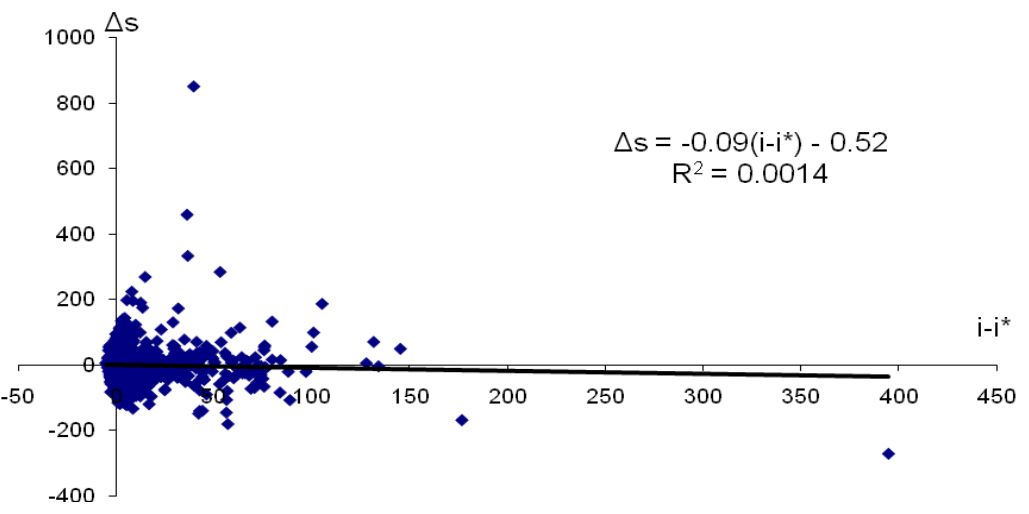

\section{Figure 4. US Common Factors and Transition Probability}

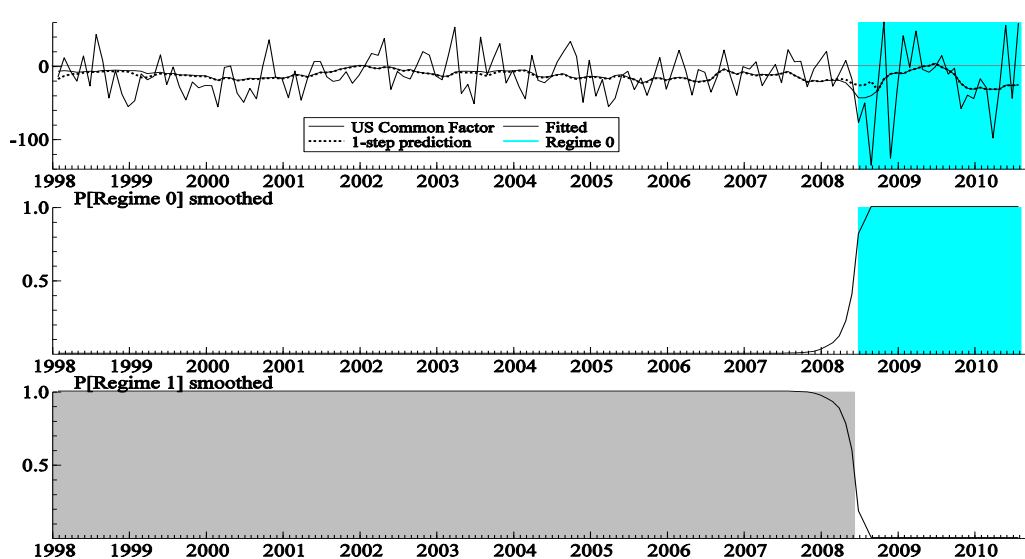

